\title{
Body image, self-esteem, and quality of life in children and adolescents with inflammatory bowel disease in a tertiary hospital in South Korea
}

\author{
Da Jeong Kum ${ }^{1}$, Kyung-Sook Bang ${ }^{2}$ \\ ${ }^{1}$ Doctoral Candidate, College of Nursing, Seoul National University, Seoul; ${ }^{2}$ Professor, College of Nursing · Research Institute of Nursing Science, Seoul National \\ University, Seoul, Korea
}

\begin{abstract}
Purpose: This study aimed to examine body image, self-esteem, and quality of life (QOL) in children and adolescents with inflammatory bowel disease (IBD) and to analyze factors influencing QOL. Methods: This descriptive study involved 87 participants at a tertiary hospital aged 10 to 18 years who were diagnosed with IBD. Body image, self-esteem, and QOL were measured. Descriptive analysis, the independent t-test, the Mann-Whitney U test, analysis of variance, Pearson correlation analysis, and stepwise multiple regression were used for data analysis. Results: The average score was $16.95 \pm 3.55$ for body image, $31.32 \pm 5.25$ for self-esteem, and $78.64 \pm 15.98$ for QOL. Height, weight, hospitalization experience, current symptoms, and consumption of oral steroids showed statistically significant effects on QOL. The most significant predictors of QOL were self-esteem ( $\beta=.31, p=.002)$, body image $(\beta=.28, p=.005)$, number of symptoms ( $\beta$ $=-.25, p=.004)$, and number of hospitalizations in the last year $(\beta=-.24, p=.004)$. Conclusion: To improve the QOL of children and adolescents with IBD, it is necessary to evaluate self-esteem, body image, and physical problems. In addition, various intervention strategies to improve self-esteem and body image and to reduce physical discomfort should be developed.
\end{abstract}

Key words: Child; Adolescent; Inflammatory bowel diseases; Quality of life

\section{Corresponding author Kyung-Sook Bang}

College of Nursing, Seoul National

University, 103 Daehak-ro, Jongno-gu,

Seoul 03080, Korea

TEL: +82-2-740-8819

FAX: +82-2-765-4103

E-MAIL: ksbang@snu.ac.kr

Received Feb 22, 2021

Revised Mar 22, 2021

Accepted Mar 30, 2021

\section{INTRODUCTION}

Inflammatory bowel disease (IBD) causes chronic inflammation of the gastrointestinal tract with repeated exacerbation or relief of symptoms such as anemia, diarrhea, and abdominal pain, which are accompanied by symptoms such as weight loss, fatigue, and fever. IBD includes ulcerative colitis (UC) and Crohn's disease (CD), and can be classified according to whether the lesions are localized in the large intestine or present throughout the gastrointestinal tract [1]. IBD is highly prevalent in North America and Northern Europe, and its prevalence has been rapidly increasing in recent years in the Middle East and Asia, including in South Korea, where it has become steadily more common since the 1990s [2].

IBD primarily occurs between the ages of 10 and 25, and $10 \%-15 \%$ of all patients are diagnosed before age 18 [3]. In particular, in the case of $\mathrm{CD}$, the highest proportion of indivi- duals diagnosed with $\mathrm{CD}$ is in their 20s, and approximately $25 \%$ of patients are diagnosed before age 19 [3,4]. Although the number of patients with IBD has not been increasing worldwide since the 2000s, IBD has been acknowledged as an important health issue due to its consistently increasing incidence in children and adolescents [5]. IBD in children and adolescents, unlike in adults, often causes extensive inflammation in the entire large intestine, and the symptoms of diarrhea and melena are typically more severe than in adults $[3,6]$. Moreover, the condition can include symptoms such as growth impairment and delayed puberty in children and adolescents. Therefore, IBD requires particular attention, since it can cause problems that persist even after the gastrointestinal symptoms are resolved [3].

In particular, children and adolescents with chronic diseases are reported to have a worse body image and lower self-esteem than their healthy peers $[7,8]$. In children and ado- 
lescents with IBD, delays in growth, fatigue, and decreased physical strength cause changes in the body $[9,10]$, and people with the condition often perceive feeling unclean due to symptoms such as diarrhea [11]. They also may have a negative perception of themselves due to their smaller size and paler skin compared to their peers [11]. Furthermore, treatments performed over the course of the disease can lead to a feeling of loss of control, and difficulties in curing the disease and uncertainties about treatment progress can cause anxiety, depression, and fear [1,11]. As such, children and adolescents with IBD experience changes in their self-concept because of the disease, and such changes in self-concept are reported to be closely associated with quality of life (QOL) [10]. Therefore, holistic nursing must be provided for adolescents to address social and psychological problems in addition to physical problems related to IBD.

Studies are being conducted worldwide to identify and mitigate sociopsychological problems in children and adolescents with IBD, including research on the characteristics of the disease in children and adolescents [6] and various social and psychological factors such as body image, self-esteem, and QOL [1,11-13]. However, interest in IBD in South Korea has only grown in recent years, and the development of diagnosis and treatment guidelines only began in the 2000s. Studies on QOL for certain groups of individuals with IBD [14,15] have been conducted in South Korea, but they are extremely insufficient, and most studies have been conducted on adults, making it a challenge to find studies on children and adolescents.

Therefore, this study investigated the body image, self-esteem, and QOL of children and adolescents with IBD, and identified associated factors. Specifically, this study 1) measured the body image, self-esteem, and QOL of the participants; 2) compared differences in body image, self-esteem, and QOL according to the participants' general characteristics; 3) identified correlations between the participants' general characteristics and their body image, self-esteem, and QOL; and 4) identified factors that affected the participants' QOL.

\section{METHODS}

Ethics statement: This study was approved by the Institutional Review Board of Seoul National University Hospital (No. 1912097-1089). Informed consent was obtained from the participants.

\section{Study Design}

This descriptive research study was designed to measure the levels of body image, self-esteem, and QOL of children and adolescents with IBD, and to identify correlations between those variables and factors that influence their QOL.

\section{Participants}

The participants of this study were children and adolescents diagnosed with IBD who were receiving treatment at a tertiary hospital located in Seoul, South Korea. The specific criteria were as follows: 1 ) children and adolescents with IBD aged 10 years (fifth grade, elementary school) to 18 years (third grade, high school) who were undergoing outpatient or inpatient treatment; 2) children or adolescents, and their guardians, who understood the purpose and method of this research and agreed to participate in the study; and 3) those who could read and respond to the questionnaire with no communication problems.

The number of study participants required for regression analysis was calculated using the $G^{*}$ Power 3.1 program; with a medium effect size of .15 , significance level of .05 , test power of .80 , and four explanatory variables [16], 85 participants were required. An intended sample size of 94 participants was then set, expecting a withdrawal rate of $10 \%$. A total of 90 participants responded to the questionnaire, and after excluding three participants who submitted questionnaires with missing responses, 87 participants were finally analyzed.

\section{Measurements}

\section{1) General characteristics}

Sex, date of birth, school, diagnosis, time of diagnosis, height, and body weight were investigated as general characteristics. As factors related to IBD, the study investigated recent body weight changes, the number of hospitalizations in the last year, the number of surgical operations experienced, symptoms experienced, the severity of symptoms, oral medication intake, oral steroid intake, whether participants received regular injections, and whether participants had undertaken new dietary regimens.

Height and body weight were measured on the same day in the outpatient clinic or ward, and participants were asked whether their current body weight had changed. Body mass index (BMI) was calculated as kilograms per meters squared based on participants' reported height and body weight. Height and body weight were interpreted based on the 2017 Korean National Growth Charts. Thus, short stature was defined as a height less than the third percentile for a given age, and underweight was defined as a body weight less than the fifth percentile for a given age [17]. Participants recorded their number of hospitalizations in the last year and the number of 
operations they had undergone since their diagnosis. Symptoms were identified using participants' responses to seven IBD-related symptom items (abdominal pain, melena, diarrhea, discomfort in the anus, fatigue, fever, and joint pain), and the severity of symptoms was assessed using a 0-10 numeric rating scale. The participants also recorded the number of medications being taken at the time of response, whether their medications contained oral steroids, and, if they received regular injections, the name and schedule of the injections (e.g., infliximab or adalimumab). Additionally, participants answered whether they were undergoing diet control, such as consuming or avoiding a particular food or taking dietary supplements.

\section{2) Body image}

Body image was measured using Harter's [18] Self-Perception Profile for Children (SPPC), adapted and standardized into Korean by Park and Chung [19]. This tool has a total of six sub-sections: five sections for competence or suitability and one for assessing overall self-esteem. The five sections are scholastic competence, social competence, athletic competence, physical appearance, and behavioral conduct. Overall self-esteem is evaluated in a section on global self-worth. There are 36 questions in total (six questions for each section).

Harter [18] stated that particular sections could be selected and surveyed according to the interest of the researcher, as the tool is divided into sections. The physical appearance section was used for this study to measure participants' degree of satisfaction and thoughts regarding their body and appearance. The six questions in each section are divided into positive and negative statements and measured on a 4-point scale. The score ranges from 6 to 24 points, with higher scores reflecting a more positive body image. In the study by Park and Chung [19], the tool showed a Cronbach's $\alpha$ value of .80 . In this study, it was .71.

\section{3) Self-esteem}

Self-esteem was measured using Rosenberg's Self-esteem Scale (RSE), which Jon [20] adapted into Korean. The tool consists of a total of 10 questions: five positive and five negative. Each question is measured on a 4-point scale, and scores range from 10 to 40, with higher scores reflecting higher self-esteem. The tool can be used for children of all age groups (school age or above) due to the simplicity of the questions, and a validity analysis was conducted for elementary school, middle school, high school, and college students in South Korea. In the study that Jeong et al. [21] conducted among elementary school, middle school, and high school students, the tool showed Cronbach's $\alpha$ values of .78 for elementary school students, .84 for middle school students, and .83 for high school students.
The Cronbach's $\alpha$ value in this study was .83 .

\section{4) Quality of life}

The QOL was measured using the Korean version of the health-related quality of life measurement tool for adolescents (4.0 Generic Core Scale), which was initially developed by Varni et al. [22] and adapted into Korean by Choi [23], who verified its validity. This tool consists of a total of 23 questions and is divided into four sub-sections: physical functioning (eight questions), emotional functioning (five questions), social functioning (five questions), and school functioning (five questions). Each question is measured from 0 to 4 points. After the measurement, a score of 4 points is converted into a score of 0 points, 3 into 25, 2 into 50, 1 into 75, and 0 into 100, with higher scores reflecting a higher QOL. In the study by Choi [23], the tool showed a Cronbach's $\alpha$ value of .93. The Cronbach's $\alpha$ value in this study was 93 .

\section{Data Collection Procedure}

This study was conducted after obtaining approval from the Institutional Review Board of Seoul National University Hospital (No. 1912-097-1089). It was conducted after first explaining the study to the medical department and head nurses of the outpatient clinic and ward, respectively. Researchers visited outpatients and ward patients to confirm that candidates satisfied the selection criteria and obtain permission for data collection. Before conducting the survey, researchers also explained the study's purpose and method to the children or adolescents and their guardians and obtained their informed consent for participating in this study. The survey was conducted after obtaining consent from a guardian for participants under the age of 12 who expressed their willingness to participate in the study on the assent form. Children and adolescents directly answered the questionnaire, and guardians assisted with questions in the general characteristics section that were difficult for participants to answer (e.g., the time of diagnosis, the number of oral medications taken). It took approximately 5-10 minutes to complete the questionnaire. Data collection was conducted from January 2020 to November 2020.

\section{Data Analysis}

Data were analyzed using SPSS version 26 (IBM Corp., Armonk, NY, USA). In analyzing the participants' general characteristics, body image, self-esteem, and QOL, descriptive statistics were used to derive the real numbers and percentages, mean, and standard deviation. The t-test, Mann-Whitney $U$ test, and analysis of variance (ANOVA) were also per- 
formed to compare differences in body image, self-esteem, and QOL according to participants' general characteristics. When performing these three tests, continuous variables, such as the number of hospitalizations in the last year and number of operations since diagnosis, were converted into categorical data. The correlations between the major variables were analyzed using Pearson's correlation coefficients. The factors influencing the QOL were confirmed using stepwise multiple regression analysis.

\section{RESULTS}

\section{General Characteristics}

Fifty-three participants were male $(60.9 \%)$ and 34 were female $(39.1 \%)$. Eleven participants were in elementary school (12.6\%), 37 in middle school $(42.5 \%)$, and 39 in high school (44.8\%), of whom 72 (82.8\%) had CD and 15 (17.2\%) had UC. It was most common to have been diagnosed within the past 1-5 years (37 patients; $42.5 \%$ ), followed by more than 5 years ago (30 patients; $34.5 \%$ ), and then less than 1 year ago (20 patients; $23.0 \%)$.

There were 39 participants with a BMI of less than $18.5 \mathrm{~kg} / \mathrm{m}^{2}$ (44.8\%), 34 with a BMI of more than $18.5 \mathrm{~kg} / \mathrm{m}^{2}$ but less than 23 $\mathrm{kg} / \mathrm{m}^{2}(39.1 \%)$, and 14 with a BMI higher than $23 \mathrm{~kg} / \mathrm{m}^{2}(16.1 \%)$. Eight participants (9.2\%) had a short stature, and 16 participants (18.4\%) were underweight. Forty-eight participants (55.2\%) had been hospitalized within the last year and 27 (31.0\%) had undergone surgery. In addition, 63 patients (72.4\%) experienced symptoms related to IBD. Moreover, 12 participants $(13.8 \%)$ took oral steroids, 51 (58.6\%) regularly received injections, and $61(70.1 \%)$ were undergoing diet control (Table 1).

\section{Body Image, Self-esteem, and Quality of Life}

The average scores were $16.95 \pm 3.55$ points out of 24 for body image, $31.32 \pm 5.25$ points out of 40 for self-esteem, and $78.64 \pm 15.98$ points out of 100 for QOL. For the sub-sections regarding QOL, school functioning (71.60 \pm 19.68 points) scored the lowest and social functioning $(87.81 \pm 15.45$ points) scored the highest (Table 2).

\section{Body Image, Self-esteem, and Quality of Life Accord- ing to General Characteristics}

No statistically significant difference was found in body image and self-esteem according to participants' general characteristics. However, the QOL section showed a significant difference according to height, body weight, hospitalizations in the last year, symptoms experienced, and intake of oral ste- roids. The QOL score was lower in those with short stature $(\mathrm{t}=2.08, p=.041)$ and for those who were underweight $(\mathrm{t}=2.17$, $p=.033$ ) than in their counterparts. In addition, the QOL score was lower in those who had been hospitalized in the last year $(\mathrm{t}=2.64, p=.010)$, in those experiencing symptoms $(\mathrm{Z}=3.71$, $p<.001)$, and in those taking oral steroids $(\mathrm{t}=2.65, p=.010)$ than in their respective counterparts. QOL was found to have a significant difference according to weight change using ANOVA, but there was no statistically significant difference in the post-hoc analysis (Table 1).

\section{Correlations between the Variables}

QOL showed a significant negative correlation with the number of hospitalizations in the last year $(\mathrm{r}=-.35, p=.001)$, number of operations $(\mathrm{r}=-.27, p=.011)$, number of symptoms experienced $(\mathrm{r}=-.41, p<.001)$, and severity of the symptoms $(\mathrm{r}=-.36, p=.001)$. In addition, QOL showed a significant positive correlation with body image $(\mathrm{r}=.50, p<.001)$ and self-esteem $(\mathrm{r}=.54, p<.001)$ (Table 3$)$.

\section{Factors Affecting Quality of Life}

In this study, QOL was significantly different according to height, body weight, hospitalization experiences in the last year, symptoms experienced, and intake of oral steroids. Furthermore, the number of hospitalizations in the last year, number of operations, symptoms experienced, the severity of symptoms, body image, and self-esteem showed significant correlations with QOL. To identify the factors that affected QOL, stepwise multiple regression analysis was performed. First, the Durbin-Watson index was 1.95 , which is close to 2 . Thus, it was determined that there was no autocorrelation. The variance inflation factor was 1.08 to 1.52 , which was less than 10 , and the tolerance was 0.66 to 0.93 , which was more than 0.1 , confirming a lack of multicollinearity.

As a result of the stepwise multiple regression analysis, self-esteem, body image, number of symptoms, and number of hospitalizations in the last year were selected for the final model. The variable that had the greatest impact on QOL was self-esteem $(\beta=.31, p=.002)$, and the explanatory power of the entire model was $49 \%$ (Table 4 ).

\section{DISCUSSION}

This study was conducted to obtain insights into the level of body image, self-esteem, and QOL of children and adolescents with IBD and to identify associated factors in order to provide basic data for understanding nursing needs for children and adolescents with IBD. 
Table 1. Comparisons of Body Image, Self-esteem, and Quality of Life According to General Characteristics $(N=87)$

\begin{tabular}{|c|c|c|c|c|c|c|c|c|}
\hline \multirow{2}{*}{ Variables } & \multirow{2}{*}{ Categories } & \multirow{2}{*}{$\mathrm{n}(\%)$} & \multicolumn{2}{|c|}{ Body image } & \multicolumn{2}{|c|}{ Self-esteem } & \multicolumn{2}{|c|}{ Quality of life } \\
\hline & & & $\mathrm{M} \pm \mathrm{SD}$ & $\operatorname{tor} \mathrm{F}(p)$ & $\mathrm{M} \pm \mathrm{SD}$ & t or $F(p)$ & $\mathrm{M} \pm \mathrm{SD}$ & t or F $(p)$ \\
\hline Sex & $\begin{array}{l}\text { Male } \\
\text { Female }\end{array}$ & $\begin{array}{l}53(60.9) \\
34(39.1)\end{array}$ & $\begin{array}{l}17.00 \pm 3.35 \\
16.88 \pm 3.91\end{array}$ & $\begin{array}{l}0.15 \\
(.881)\end{array}$ & $\begin{array}{l}31.74 \pm 5.35 \\
30.68 \pm 5.10\end{array}$ & $\begin{array}{l}0.92 \\
(.362)\end{array}$ & $\begin{array}{l}80.95 \pm 14.81 \\
75.06 \pm 17.26\end{array}$ & $\begin{array}{l}1.69 \\
(.094)\end{array}$ \\
\hline Educational level & $\begin{array}{l}\text { Elementary school } \\
\text { Middle school } \\
\text { High school }\end{array}$ & $\begin{array}{l}11(12.6) \\
37(42.5) \\
39(44.8)\end{array}$ & $\begin{array}{l}17.36 \pm 4.30 \\
17.59 \pm 3.10 \\
16.23 \pm 3.70\end{array}$ & $\begin{array}{l}1.50 \\
(.229)\end{array}$ & $\begin{array}{l}32.27 \pm 5.27 \\
31.49 \pm 5.17 \\
30.90 \pm 5.41\end{array}$ & $\begin{array}{l}0.32 \\
(.727)\end{array}$ & $\begin{array}{l}82.11 \pm 18.58 \\
78.38 \pm 14.26 \\
77.93 \pm 17.04\end{array}$ & $\begin{array}{c}0.30 \\
(.742)\end{array}$ \\
\hline Diagnosis & $\begin{array}{l}\mathrm{CD} \\
\mathrm{UC}\end{array}$ & $\begin{array}{l}72(82.8) \\
15(17.2)\end{array}$ & $\begin{array}{l}16.86 \pm 3.54 \\
17.40 \pm 3.72\end{array}$ & $\begin{array}{l}0.53 \\
(.596)\end{array}$ & $\begin{array}{l}31.42 \pm 5.20 \\
30.87 \pm 5.68\end{array}$ & $\begin{array}{l}0.37 \\
(.714)\end{array}$ & $\begin{array}{l}77.84 \pm 16.02 \\
82.54 \pm 15.72\end{array}$ & $\begin{array}{l}1.04 \\
(.303)\end{array}$ \\
\hline $\begin{array}{l}\text { Time since } \\
\text { diagnosis (year) }\end{array}$ & $\begin{array}{l}<1 \\
\geq 1 \&<5 \\
\geq 5\end{array}$ & $\begin{array}{l}20(23.0) \\
37(42.5) \\
30(34.5)\end{array}$ & $\begin{array}{l}17.70 \pm 3.83 \\
16.54 \pm 3.43 \\
16.97 \pm 3.56\end{array}$ & $\begin{array}{l}0.69 \\
(.506)\end{array}$ & $\begin{array}{l}31.30 \pm 5.38 \\
31.03 \pm 5.20 \\
31.70 \pm 5.38\end{array}$ & $\begin{array}{l}0.13 \\
(.875)\end{array}$ & $\begin{array}{l}75.98 \pm 15.78 \\
80.46 \pm 14.73 \\
78.19 \pm 17.76\end{array}$ & $\begin{array}{l}0.53 \\
(.594)\end{array}$ \\
\hline $\begin{array}{l}\text { Body mass index } \\
\left(\mathrm{kg} / \mathrm{m}^{2}\right)\end{array}$ & $\begin{array}{l}<18.5 \\
\geq 18.5 \&<23 \\
\geq 23\end{array}$ & $\begin{array}{l}39(44.8) \\
34(39.1) \\
14(16.1)\end{array}$ & $\begin{array}{l}16.77 \pm 3.72 \\
17.32 \pm 3.49 \\
16.57 \pm 3.41\end{array}$ & $\begin{array}{c}0.31 \\
(.732)\end{array}$ & $\begin{array}{l}31.51 \pm 4.78 \\
31.06 \pm 5.86 \\
31.43 \pm 5.32\end{array}$ & $\begin{array}{l}0.07 \\
(.933)\end{array}$ & $\begin{array}{l}74.47 \pm 15.98 \\
83.09 \pm 14.74 \\
79.50 \pm 16.90\end{array}$ & $\begin{array}{l}2.77 \\
(.068)\end{array}$ \\
\hline Short stature & $\begin{array}{l}\text { Yes } \\
\text { No }\end{array}$ & $\begin{array}{c}8(9.2) \\
79(90.8)\end{array}$ & $\begin{array}{l}16.37 \pm 2.56 \\
17.01 \pm 3.65\end{array}$ & $\begin{array}{l}0.48 \\
(.631)\end{array}$ & $\begin{array}{l}30.88 \pm 6.27 \\
31.38 \pm 5.18\end{array}$ & $\begin{array}{l}0.25 \\
(.802)\end{array}$ & $\begin{array}{l}67.66 \pm 16.20 \\
79.76 \pm 15.63\end{array}$ & $\begin{array}{l}2.08 \\
(.041)\end{array}$ \\
\hline Underweight & $\begin{array}{l}\text { Yes } \\
\text { No }\end{array}$ & $\begin{array}{l}16(18.4) \\
71(81.6)\end{array}$ & $\begin{array}{l}17.63 \pm 3.69 \\
16.80 \pm 3.53\end{array}$ & $\begin{array}{l}0.84 \\
(.406)\end{array}$ & $\begin{array}{l}32.31 \pm 5.15 \\
31.10 \pm 5.29\end{array}$ & $\begin{array}{l}0.83 \\
(.407)\end{array}$ & $\begin{array}{l}71.00 \pm 14.85 \\
80.37 \pm 15.81\end{array}$ & $\begin{array}{l}2.17 \\
(.033)\end{array}$ \\
\hline $\begin{array}{l}\text { Recent body weight } \\
\text { change }\end{array}$ & $\begin{array}{l}\text { Increased } \\
\text { Maintained } \\
\text { Decreased }\end{array}$ & $\begin{array}{l}41(47.1) \\
28(32.2) \\
18(20.7)\end{array}$ & $\begin{array}{l}17.22 \pm 0.54 \\
17.18 \pm 0.68 \\
16.00 \pm 0.87\end{array}$ & $\begin{array}{l}0.82 \\
(.446)\end{array}$ & $\begin{array}{l}31.12 \pm 0.87 \\
32.46 \pm 0.87 \\
30.00 \pm 1.28\end{array}$ & $\begin{array}{l}1.27 \\
(.286)\end{array}$ & $\begin{array}{l}79.59 \pm 15.10 \\
83.04 \pm 16.07 \\
69.69 \pm 15.04\end{array}$ & $\begin{array}{c}4.26 \\
(.017)^{*}\end{array}$ \\
\hline $\begin{array}{l}\text { Hospitalization } \\
\text { experience in the } \\
\text { last year }\end{array}$ & $\begin{array}{l}\text { Yes } \\
\text { No }\end{array}$ & $\begin{array}{l}48(55.2) \\
39(44.8)\end{array}$ & $\begin{array}{l}16.73 \pm 3.80 \\
17.23 \pm 3.26\end{array}$ & $\begin{array}{l}0.65 \\
(.516)\end{array}$ & $\begin{array}{l}30.79 \pm 5.48 \\
31.97 \pm 4.94\end{array}$ & $\begin{array}{l}1.05 \\
(.299)\end{array}$ & $\begin{array}{l}74.71 \pm 16.39 \\
83.50 \pm 14.21\end{array}$ & $\begin{array}{l}2.64 \\
(.010)\end{array}$ \\
\hline $\begin{array}{l}\text { Experience of } \\
\text { operation }\end{array}$ & $\begin{array}{l}\text { Yes } \\
\text { No }\end{array}$ & $\begin{array}{l}27(31.0) \\
60(69.0)\end{array}$ & $\begin{array}{l}17.30 \pm 2.83 \\
16.80 \pm 3.85\end{array}$ & $\begin{array}{l}0.60 \\
(.550)\end{array}$ & $\begin{array}{l}31.30 \pm 5.61 \\
31.33 \pm 5.13\end{array}$ & $\begin{array}{l}0.03 \\
(.976)\end{array}$ & $\begin{array}{l}76.77 \pm 16.47 \\
79.49 \pm 17.03\end{array}$ & $\begin{array}{l}0.73 \\
(.466)\end{array}$ \\
\hline $\begin{array}{l}\text { Experience of } \\
\text { symptoms }\end{array}$ & $\begin{array}{l}\text { Yes } \\
\text { No }\end{array}$ & $\begin{array}{l}63(72.4) \\
24(27.6)\end{array}$ & $\begin{array}{l}16.51 \pm 3.52 \\
18.13 \pm 3.44\end{array}$ & $\begin{array}{l}1.93 \\
(.057)\end{array}$ & $\begin{array}{l}30.73 \pm 5.23 \\
32.88 \pm 5.09\end{array}$ & $\begin{array}{l}1.72 \\
(.089)\end{array}$ & $\begin{array}{l}74.97 \pm 16.04 \\
88.32 \pm 11.24\end{array}$ & $\begin{array}{c}3.71 \\
(<.001)^{\dagger}\end{array}$ \\
\hline Oral steroid use & $\begin{array}{l}\text { Yes } \\
\text { No }\end{array}$ & $\begin{array}{l}12(13.8) \\
75(86.2)\end{array}$ & $\begin{array}{l}16.25 \pm 4.31 \\
17.07 \pm 3.44\end{array}$ & $\begin{array}{l}0.74 \\
(.463)\end{array}$ & $\begin{array}{l}30.33 \pm 5.57 \\
31.48 \pm 5.22\end{array}$ & $\begin{array}{l}0.70 \\
(.486)\end{array}$ & $\begin{array}{l}67.67 \pm 15.05 \\
80.41 \pm 15.50\end{array}$ & $\begin{array}{l}2.65 \\
(.010)\end{array}$ \\
\hline Regular injections & $\begin{array}{l}\text { Yes } \\
\text { No }\end{array}$ & $\begin{array}{l}51(58.6) \\
36(41.4)\end{array}$ & $\begin{array}{l}16.57 \pm 3.53 \\
17.50 \pm 3.56\end{array}$ & $\begin{array}{l}1.21 \\
(.231)\end{array}$ & $\begin{array}{l}30.43 \pm 5.46 \\
32.58 \pm 4.73\end{array}$ & $\begin{array}{l}1.91 \\
(.059)\end{array}$ & $\begin{array}{l}77.20 \pm 16.12 \\
80.71 \pm 15.78\end{array}$ & $\begin{array}{l}1.01 \\
(.316)\end{array}$ \\
\hline $\begin{array}{l}\text { Change in dietary } \\
\text { regimen }\end{array}$ & $\begin{array}{l}\text { Yes } \\
\text { No }\end{array}$ & $\begin{array}{l}61(70.1) \\
26(29.9)\end{array}$ & $\begin{array}{l}17.10 \pm 3.69 \\
16.62 \pm 3.25\end{array}$ & $\begin{array}{l}0.58 \\
(.565)\end{array}$ & $\begin{array}{l}31.74 \pm 4.86 \\
30.35 \pm 6.06\end{array}$ & $\begin{array}{l}1.13 \\
(.260)\end{array}$ & $\begin{array}{l}79.28 \pm 15.85 \\
77.17 \pm 16.50\end{array}$ & $\begin{array}{l}0.03 \\
(.974)\end{array}$ \\
\hline
\end{tabular}

*The post-hoc analysis result was not statistically significant; ${ }^{\dagger}$ Z-score, calculated by Mann-Whitney U test; CD, Crohn's disease; UC, ulcerative colitis.

Table 2. Levels of Body Image, Self-esteem, and Quality of Life $(N=87)$

\begin{tabular}{lccr}
\hline Variables & M \pm SD & Min & Max \\
\hline Body image & $16.95 \pm 3.55$ & 10.00 & 24.00 \\
Self-esteem & $31.32 \pm 5.25$ & 16.00 & 40.00 \\
Quality of life & $78.64 \pm 15.98$ & 32.61 & 100.00 \\
$\quad$ Physical functioning & $78.34 \pm 19.33$ & 18.75 & 100.00 \\
$\quad$ Emotional functioning & $77.01 \pm 23.30$ & 15.00 & 100.00 \\
$\quad$ Social functioning & $87.81 \pm 15.45$ & 40.00 & 100.00 \\
$\quad$ School functioning & $71.60 \pm 19.68$ & 5.00 & 100.00 \\
\hline
\end{tabular}

Max, maximum; Min, minimum. 
Table 3. Correlations among Variables $(N=87)$

\begin{tabular}{|c|c|c|c|c|c|c|c|c|}
\hline \multirow{2}{*}{ Variables } & 1 & 2 & 3 & 4 & 5 & 6 & 7 & 8 \\
\hline & $\mathrm{r}(p)$ & $\mathrm{r}(p)$ & $\mathrm{r}(p)$ & $r(p)$ & $r(p)$ & $\mathrm{r}(p)$ & $r(p)$ & $\mathrm{r}(p)$ \\
\hline 1. Body mass index & 1 & & & & & & & \\
\hline 2. Number of hospitalizations in the last year & $-.17(.120)$ & 1 & & & & & & \\
\hline 3. Number of operations & $-.07(.508)$ & $.56(<.001)$ & 1 & & & & & \\
\hline 4. Number of symptoms & $-.25(.018)$ & $.27(.012)$ & $.08(.458)$ & 1 & & & & \\
\hline 5. Severity of symptoms & $-.14(.204)$ & $.07(.512)$ & $.12(.267)$ & $.54(<.001)$ & 1 & & & \\
\hline 6. Body image & $-.06(.572)$ & $-.08(.492)$ & $-.12(.285)$ & $-.12(.278)$ & $-.29(.007)$ & 1 & & \\
\hline 7. Self-esteem & $-.07(.500)$ & $-.07(.503)$ & $-.08(.438)$ & $-.21(.055)$ & $-.18(.094)$ & $.57(<.001)$ & 1 & \\
\hline 8. Quality of life & $.17(.116)$ & $-.35(.001)$ & $-.27(.011)$ & $-.41(<.001)$ & $-.36(.001)$ & $.50(<.001)$ & $.54(<.001)$ & 1 \\
\hline
\end{tabular}

Table 4. Factors Influencing Quality of Life $(N=87)$

\begin{tabular}{|c|c|c|c|c|c|c|c|}
\hline Variables & $\mathrm{B}$ & SE & $\beta$ & $\mathrm{t}$ & $p$ & TOL & VIF \\
\hline Constant & 34.15 & 8.43 & & 4.05 & $<.001$ & & \\
\hline Self-esteem & 0.95 & 0.29 & .31 & 3.23 & .002 & 0.66 & 1.52 \\
\hline Body image & 1.24 & 0.43 & .28 & 2.89 & .005 & 0.68 & 1.47 \\
\hline Number of symptoms & -2.20 & 0.74 & -.25 & 2.97 & .004 & 0.89 & 1.12 \\
\hline \multirow[t]{2}{*}{ Number of hospitalizations in the last year } & -1.71 & 0.57 & -.24 & 2.98 & .004 & 0.93 & 1.08 \\
\hline & \multicolumn{7}{|c|}{$\mathrm{R}^{2}=.49$, Adj. $\mathrm{R}^{2}=.47, \mathrm{~F}=19.98, p<.001$} \\
\hline
\end{tabular}

TOL, tolerance; VIF, variance inflation factor.

A total of 87 participants were studied, of whom $72(82.8 \%)$ had CD and 15 (17.2\%) had UC. Although the number of patients with UC is twice as high as the number of patients with CD among all patients with IBD in South Korea, CD is more common in patients in their 20s and 30s than UC, which has a higher prevalence for patients in their 40s and 50s [4]. Moreover, studies have suggested that $\mathrm{CD}$ is more common than UC in children [3], which is why the percentage of participants with $C D$ in this study was high.

In addition, eight participants $(9.8 \%)$ had height below the third percentile and 16 participants $(18.4 \%)$ below the fifth percentile. This supports previous studies that reported growth disorders occurring in children and adolescents with IBD $[3,6]$.

In this study, the mean body image score of children and adolescents with IBD was 16.95 points. This is similar, but slightly lower, than the mean initial body image score (18.0 points) and the mean body image score six months after diagnosis (17.4 points) in children and adolescents who were diagnosed with chronic diseases such as asthma, diabetes, epilepsy, allergies, and rheumatoid arthritis [24]. The mean body image scores of healthy late school-aged children were 15.77 points for males and 15.69 points for females [25], but they were 17.00 points for males and 16.88 points for females in this study, showing a higher score than that of the healthy late school-aged children in the previous study. Children with chronic diseases generally reported having a worse body image compared to healthy children, as shown in another study comparing children with chronic diseases to children without diseases [7]. With these contrasting results, there seem to be limitations in directly comparing the results of this study with the scores reported at the time of the tool's development or with other studies, as there are differences in the general characteristics of the participants, research methods, and environment.

The mean self-esteem score of children and adolescents with IBD in this study was 31.32 points. In a study of children with attention deficit hyperactivity disorder, the mean self-esteem score was 29.85 points [26], while that of children with obesity was 30.02 points [21]. The mean self-esteem score of participants in this study was similar, though slightly higher. The level of self-esteem appeared to be lower when individuals had externally visible symptoms such as obesity, spina bifida, and cerebral palsy than among those with symptoms related to chronic diseases such as diabetes and IBD [8], which seems to have been reflected in this study. 
The mean QOL score of children and adolescents with IBD in this study was 78.64 points. This result is similar to the mean QOL score of children and adolescents who were newly diagnosed with IBD internationally (78.46 points) [13]. Meanwhile, the mean QOL for those who received hematopoietic stem cell transplantation in South Korea was 72.26 points [27], showing a lower mean QOL than the participants in this study. However, in a study by Jung et al. [15], the QOL score of adolescents with IBD in South Korea was 83.34, which was higher than that of the participants in this study. Although the participants' ages in the previous study and in the current study were similar, the shorter period of time since diagnosis and the lower number of operations experienced by participants in this study likely affected the severity of the disease, thus explaining the differences in the study results. Disease severity scales for pediatric IBD have not been used frequently in South Korea, but using disease severity scales such as the Pediatric Crohn's Disease Activity Index (PCDAI) and Pediatric Ulcerative Colitis Activity Index (PUCAI) for future studies is recommended to help enhance researchers' and clinicians' understanding of this issue [3].

In this study, no factors were identified as having a statistically significant influence on body image and self-esteem. The factors that had a statistically significant effect on QOL were height, body weight, hospitalization experiences in the last year, symptoms experienced, and use of oral steroids. First, lower QOL scores for patients with short stature and who were underweight showed statistical significance. The proportions of both were high, with $9.2 \%$ of participants having short stature and $18.4 \%$ being underweight. Such growth disorders persist even after the completion of treatment for IBD and are related to delayed puberty and musculoskeletal problems [3]. Interventions such as nutritional supplements and efforts to resolve loss of appetite will be needed in addition to regular checkups on patients' growth status.

The finding of lower QOL scores for patients who had been hospitalized in the last year also showed statistical significance. The frequency of hospitalization for patients with IBD, which has a high rate of outpatient treatment, indicates greater disease severity. This is consistent with the results of a previous study of adult $C D$ patients that showed that the frequency of hospitalizations and disease severity had a significant effect on QOL [14]. In addition, lower QOL scores for patients experiencing symptoms related to IBD showed statistical significance. This is consistent with the results of previous studies that showed that symptoms experienced by patients are a major factor affecting QOL $[14,28]$. Because symptoms worsen as the severity of the disease increases, these results indicate that the severity of the disease affects one's QOL. Lastly, taking oral steroids also appeared to lower QOL, with statistical significance. A previous study also reported that patients taking oral steroids had a low body image, and such changes in body image were reported to lead to a decrease in QOL, which is consistent with the results of this study [10]. In general, steroids are used temporarily to induce remission at the initial stage of diagnosis or to control symptoms during the acute phase. Thus, oral steroid intake indicates greater disease severity. Therefore, the severity of the disease can be interpreted as having an impact on QOL in a similar way to the results of previous studies. Examining these results, nursing interventions should consider diet control, education to promote self-care, and interventions for improving medication adherence to reduce the severity of the disease.

Meanwhile, the number of hospitalizations in the last year, the number of operations, the experience of symptoms, and the severity of symptoms all had significant negative correlations with QOL, and body image and self-esteem had significant positive correlations with the QOL. Previous studies have also demonstrated that disease severity and the experience of symptoms negatively affected QOL [10,14], and body image and self-esteem had positive correlations with QOL $[14,29]$, consistent with this study's results.

This study identified the factors that significantly affected QOL in children and adolescents with IBD, such as self-esteem, body image, the number of symptoms, and the number of hospitalizations in the last year, of which self-esteem was the most important. Since self-esteem is a crucial personal resource for patients to accept their disease and overcome difficulties, interventions such as therapeutic communication are needed to improve patients' QOL. However, in previous studies of childhood cancer and adult CD patients, although self-esteem showed a significant positive correlation with QOL, it was not confirmed to be a variable affecting QOL in the final results $[14,27]$. This discrepancy is assumed to result from differences in diagnoses or developmental stages. Therefore, additional studies are needed to verify that self-esteem affects QOL.

Body image was confirmed as a significant predictor of QOL, similar to previous studies on children with IBD and adults with $\mathrm{CD}$ that also found body image to be a meaningful predictor $[12,14]$. Therefore, it is necessary to improve QOL by improving the body image of children and adolescents with IBD. Regular evaluations are needed and related nursing interventions, such as programs incorporating cognitive-behavioral therapy, should be developed.

The number of symptoms and number of hospitalizations were also found to be significant predictors of QOL. Previous studies of IBD and childhood cancer similarly found that physical symptoms and symptom experience meaningfully affected QOL $[13,27]$. In addition, a study on CD found that 
the need for hospitalization significantly affected QOL [30]. Both the experience of symptoms and the need for hospitalization are closely related to disease severity, as mentioned earlier. Therefore, it is necessary to provide nursing interventions to improve self-care to reduce disease severity and manage symptoms to improve overall QOL.

The most significant limitation of this study is that not many previous studies have been conducted on children and adolescents with IBD in South Korea. Therefore, it was difficult to compare the results of this study with previous research. In addition, it is difficult to generalize the results of this study since it was conducted among children and adolescents with IBD in a tertiary hospital. Therefore, there is a need to conduct similar studies in various regions and institutions in the future. Nevertheless, considering the low number of studies on children and adolescents with IBD, this study is expected to provide useful data for understanding and planning appropriate interventions for IBD patients.

\section{CONCLUSION}

This study is significant because it investigated the levels of body image, self-esteem, and QOL of children and adolescents with IBD and identified associated factors to yield insights into the characteristics of children and adolescents with IBD, thereby providing basic data for enhancing nursing interventions. The results of this study showed that no significant factors affected the body image and self-esteem of study participants, but some did affect $\mathrm{QOL}$, including participants' physical growth, frequency of hospitalization, the experience of symptoms, and use of steroids. In addition, disease severity, which is associated with the need for surgery and hospitalization, the number of symptoms, and severity of symptoms, was found to be correlated with QOL. Moreover, self-esteem, body image, the number of symptoms, and the number of hospitalizations in the last year were confirmed as factors that significantly influenced QOL.

Therefore, considering the results of this study, to improve the QOL of children and adolescents with IBD, it is necessary to actively assess their self-esteem and body image. In addition, various intervention strategies to improve patients' selfesteem and body image and to reduce disease severity (i.e., the experience of symptoms and frequency of hospitalization) should be developed and provided.

\section{ORCID}

Da Jeong Kum https://orcid.org/0000-0002-8493-5588 Kyung-Sook Bang

\section{Authors' contribution}

Conceptualization: all authors; Data collection and Formal analysis: all authors; Writing-original draft, Writing-review and editing: all authors; Final approval of published version: all authors.

\section{Conflict of interest}

No existing or potential conflict of interest relevant to this article was reported.

\section{Funding}

This study was supported by "BK21 FOUR" project 'Center for Human-Caring Nurse Leaders for the Future' funded by the Ministry of Education.

\section{Data availability}

Please contact the corresponding author for data availability.

\section{Acknowledgements}

None.

\section{REFERENCES}

1. Greenley RN, Hommel KA, Nebel J, Raboin T, Li SH, Simpson P, et al. A meta-analytic review of the psychosocial adjustment of youth with inflammatory bowel disease. Journal of Pediatric Psychology. 2010;35(8):857-869.

https://doi.org/10.1093/jpepsy/jsp120

2. Yang SK, Yun S, Kim JH, Park JY, Kim HY, Kim YH, et al. Epidemiology of inflammatory bowel disease in the Songpa- Kangdong district, Seoul, Korea, 1986-2005: A KASID study. Inflammatory Bowel Diseases. 2007;14(4):542-549.

https://doi.org/10.1002/ibd.20310

3. Seo JK. Pediatric inflammatory bowel disease (IBD): Phenotypic, genetic and therapeutic differences between early-onset and adultonset IBD. Korean Journal of Pediatric Gastroenterology, Hepatology and Nutrition. 2011;14(1):1-25. https://doi.org/10.5223/kjpgn.2011.14.1.1

4. Ha JE, Jang EJ, Lim SG, Son HS. Medication use and drug expenditure in inflammatory bowel disease: Based on Korean National Health Insurance Claims Data (2010-2014). Korean Journal of Clinical Pharmacy. 2019;29(2):79-88. https://doi.org/10.24304/kjcp.2019.29.2.79

5. Kaplan GG, Ng SC. Understanding and preventing the global increase of inflammatory bowel disease. Gastroenterology. 2017;152 
(2):313-321. https:// doi.org/10.1053/j.gastro.2016.10.020

6. Sonavane AD, Sonawane P, Amarapurkar DN. Inflammatory bowel disease across the age continuum: Similarity and disparity. The Indian Journal of Pediatrics. 2018;85(11):989-994.

https://doi.org/10.1007/s12098-018-2665-5

7. Pinquart M. Body image of children and adolescents with chronic illness: A meta-analytic comparison with healthy peers. Body Image. 2013;10(2):141-148.

https://doi.org/10.1016/j.bodyim.2012.10.008

8. Pinquart M. Self-esteem of children and adolescents with chronic illness: A meta-analysis. Child: Care, Health and Development. 2013;39(2):153-161. https://doi.org/10.1111/j.1365-2214.2012.01397.x

9. Casati J, Toner BB, De Rooy EC, Drossman DA, Maunder RG. Review: Concerns of patients with inflammatory bowel disease. Digestive Diseases and Sciences. 2000;45(1):26-31. https://doi.org/10.1023/a:1005492806777

10. Saha S, Zhao YQ, Shah SA, Esposti SD, Lidofsky S, Bright R, et al. Body image dissatisfaction in patients with inflammatory bowel disease. Inflammatory Bowel Diseases. 2015;21(2):345-352. https://doi.org/10.1097/MIB.0000000000000270

11. Nicholas DB, Otley A, Smith C, Avolio J, Munk M, Griffiths AM. Challenges and strategies of children and adolescents with inflammatory bowel disease: A qualitative examination. Health and Quality of Life Outcomes. 2007;5:28.

https://doi.org/10.1186/1477-7525-5-28

12. Werner H, Landolt MA, Buehr P, Koller R, Nydegger A, Spalinger $\mathrm{J}$, et al. Changes in health-related quality of life over a 1-year follow-up period in children with inflammatory bowel disease. Quality of Life Research. 2017;26(6):1617-1626.

https://doi.org/10.1007/s11136-017-1513-9

13. Goldstein-Leever A, Bass JA, Goyal A, Maddux MH. Health-related quality of life predicts psychology referral in youth with inflammatory bowel disease. Journal of Pediatric Nursing. 2019;47: 73-77. https://doi.org/10.1016/j.pedn.2019.04.016

14. Lee YJ, Oh EG. Body image, self esteem, and health related quality of life in patients with Crohn's Disease. Korean Journal of Adult Nursing. 2014;26(4):383-392.

https://doi.org/10.7475/kjan.2014.26.4.383

15. Jung JY, Park YS, Kwon MK, Bang KS. Quality of life of adolescents with inflammatory bowel disease. Journal of Korean Clinical Nursing Research. 2012;18(2):264-274.

https://doi.org/10.22650/JKCNR.2012.18.2.264

16. Polit DF, Beck CT. Nursing research: Generating and assessing evidence for nursing practice. 10th ed. Philadelphia: Wolters Kluwer Health; 2016. p. 405-412.

17. Kim JH, Yun S, Hwang S, Shim JO, Chae HW, Lee YJ, et al. The 2017 Korean National Growth Charts for children and adolescents: Development, improvement, and prospects. Korean Journal of Pediatrics. 2018;61(5):135-149. https://doi.org/10.3345/kjp.2018.61.5.135

18. Harter S. Self-perception profile for children: Manual and questionnaires (grade 3-8) [Internet]. Denver, CO: University of Denver; 2012 [cited 2019 November 10]. Available from: https://portfolio.du.edu/SusanHarter/page/44210

19. Park YY, Chung OB. Parental childrearing, behavior, children's sibling relationships and children's self-esteem. Korean Journal of Child Studies. 1996;17(1):189-212.

20. Jon BJ. The theory of self-concept: Its history and heuristic value. Journal of the Humanities. 1973;29:103-131.

21. Jeong E, Kang SK, Kim S. The effect of obesity in youth on self-esteem: Focusing on gender difference. Korean Journal of Social Welfare Studies. 2014;45(4):267-294. https://doi.org/10.16999/kasws.2014.45.4.267

22. Varni JW, Seid M, Rode CA. The PedsQL ${ }^{\mathrm{TM}}$ : Measurement model for the pediatric quality of life inventory. Medical Care. 1999;37 (2):126-139. https://doi.org/10.1097/00005650-199902000-00003

23. Choi ES. Psychometric test of the PedsQL ${ }^{\mathrm{TM}} 4.0$ Generic Core Scale in Korean adolescents. Korean Journal of Nursing Query. 2005:14 (1):166-182.

24. Ferro MA, Tang J. Psychometric properties of the self-perception profile for children in children with chronic illness. Journal of the Canadian Academy of Child and Adolescent Psychiatry. 2017;26(2): 119-124.

25. Bang KS, Chae SM, Kim JY, Kang HJ. Relationships between body image, self-esteem and family strengths in late school aged children. Korean Parent-Child Health Journal. 2012;15(1):33-38.

26. Oh J, Ha E. Differences of behavioral problems, social competence and self-esteem between ADHD, with and without depressive symptoms: With a special focus on children and adolescents in child foster care centers. Korean Journal of Play Therapy. 2019;22 (4):445-462. https://doi.org/10.17641/KAPT.22.4.5

27. Hwang YM, Bang KS. Health-related quality of life of children and adolescents after hematopoietic stem cell transplantation. Child Health Nursing Research. 2020;26(4):402-410.

https://doi.org/10.4094/chnr.2020.26.4.402

28. IsHak WW, Pan D, Steiner AJ, Feldman E, Mann A, Mirocha J, et al. Patient-reported outcomes of quality of life, functioning, and GI/ psychiatric symptom severity in patients with inflammatory bowel disease (IBD). Inflammatory Bowel Diseases. 2017;23(5):798-803. https://doi.org/10.1097/mib.0000000000001060

29. De Boer M, Grootenhuis M, Derkx B, Last B. Health-related quality of life and psychosocial functioning of adolescents with inflammatory bowel disease. Inflammatory Bowel Diseases. 2005;11(4):400-406. https://doi.org/10.1097/01.mib.0000164024.10848.0a

30. Floyd DN, Langham S, Séverac HC, Levesque BG. The economic and quality-of-life burden of Crohn's disease in Europe and the United States, 2000 to 2013: A systematic review. Digestive Diseases and Sciences. 2015;60(2):299-312. https://doi.org/10.1007/s10620-014-3368-z 